\title{
Invenções robóticas para o Tratamento de Parkinson: pensamento computacional e formação matemática
}

\author{
Robotic Inventions for Parkinson's Treatment: computational \\ thinking and mathematical teaching
}

\author{
Greiton Toledo de Azevedo* \\ ORCID iD 0000-0002-2681-1915 \\ Marcus Vinicius Maltempi ${ }^{* *}$ \\ ORCID iD 0000-0001-5201-0348
}

\begin{abstract}
Resumo
Nosso objetivo é identificar e analisar as características do Pensamento Computacional para a formação matemática de estudantes ao longo da produção de jogos digitais e dispositivos robóticos destinados ao tratamento de sintomas da doença de Parkinson. Norteados pela metodologia de pesquisa qualitativa, a produção de dados foi realizada com alunos do Ensino Médio do IF-Goiano, em Ipameri (GO), e no Hospital Dia do Idoso, em Anápolis. O cenário formativo de pesquisa foi criado como lugar para vivenciar experiências em Matemática como modo de vida e não como ação mecânica e formalismos, que tendem a minar a forma de pensar e inventar do próprio aluno em relação aos conhecimentos matemáticos e computacionais mobilizados. No lugar de definição-exemplo-exercícios-respostas, valoriza-se a compreensão-invenção-resultados de Matemática e suas tecnologias. A hierarquia procedimental conteúdo-exemplo-exercícios é rompida nessa concepção, dando lugar à investigação e à invenção científico-tecnológica ao Parkinson. Os dados produzidos foram analisados a partir de elementos do Pensamento Computacional mobilizados durante a produção do jogo e do dispositivo robótico. Os resultados obtidos indicam características do Pensamento Computacional que se integram à formação em Matemática: algoritmo, reconhecimento de padrões, decomposição e abstração, a partir das invenções científico-tecnológicas destinadas ao tratamento e ao bem-estar de pacientes acometidos.
\end{abstract}

Palavras-chave: Formação em Matemática. Jogos Digitais. Robótica. Parkinson.

\begin{abstract}
Our goal is to identify and analyze the characteristics of Computational Thinking for mathematical students' training along the production of digital games and robotic devices for the treatment of Parkinson's disease symptoms. Guided by the qualitative research methodology, data production was carried out with high school students from IF-Goiano, in Ipameri, and at the Hospital Dia do Idoso, in Anápolis. The formative research scenario was created as a place to feel mathematics experiences as a way of life and not as mechanical action and formalisms, which tend to undermine the student's own way of thinking and inventing in relation to the mathematical and computational knowledge mobilized. In place of definition-example-exercises-answers, we

\footnotetext{
" Doutorando em Educação Matemática na Universidade Estadual Paulista "Júlio de Mesquita Filho" (Unesp). Professor e Pesquisador pelo Instituto Federal Goiano (IF-Goiano), Ipameri, Goiás, Brasil. E-mail: greiton.azevedo@ifgoiano.edu.br.

${ }_{* * *}$ Doutor em Engenharia Elétrica e de Computação pela Universidade Estadual de Campinas (Unicamp). Livre Docente em Educação Matemática e Professor da Universidade Estadual Paulista "Júlio de Mesquista Filho" (Unesp), Rio Claro, São Paulo, Brasil. E-mail: marcus.maltempi@unesp.br. Apoiado pela FAPESP (Processo 2018/14053-2) e CNPq (Processo 308563/2019-0).
} 
value understanding-invention-results of mathematics and its technologies. The procedural hierarchy contentexample-exercises is broken in this conception, giving rise to Parkinson's research and scientific-technological invention. The data produced were analyzed from elements of Computational Thinking mobilized during the production of the game and the robotic device. The results obtained indicate characteristics of Computational Thinking that are integrated into mathematics training: algorithm, pattern recognition, decomposition and abstraction, based on scientific-technological inventions for the treatment and well-being of affected patients.

Keywords: Mathematical Teaching. Digital Games. Robotics. Parkinson.

\section{Introdução}

Histórias inspiradoras marcaram realidades e foram eternizadas positivamente ao redor do mundo. Apesar das combinações perversas e grandiosamente desafiadoras na linha do tempo, pessoas engajadas devolveram esperança a tantos cenários drasticamente assolados. Nesta perspectiva, trazemos à memória vidas intrépidas que mudaram percursos e devolveram cor e vida a tantos lugares: símbolo de luta contra apartheid, Nelson Mandela (África do Sul) refundou o seu país com uma sociedade mais multiétnica, livre e democrática. Malala Yousafzai (Paquistão) colocou a sua própria vida em defesa do direito à educação. Mahatma Gandhi (Índia) mostrou que a paz e o diálogo são armas poderosas e potencialmente necessárias. Morta durante o holocausto, Anne Frank (Holanda) escreveu um diário enriquecido de pensamentos sobre a época do nazismo.

No hemisfério sul temos muitos nomes consagrados, sendo Santos Dumont um deles, que mostrou a possibilidade de desbravar as alturas com a invenção do primeiro balão dirigível e do avião 14-Bis. Contagiados por histórias de trans(formação) e invenção científica da humanidade, que ampliaram visões e deram novos sentidos ao mundo, vislumbramos a sala de aula de Matemática como lugar de invenção científico-tecnológica. Trazemos a problematização do processo de formação em Matemática a partir da invenção de dispositivos robóticos em prol do tratamento da doença de Parkinson (SANTANA et al., 2015; GONÇALVES; LEITE; PEREIRA, 2011). Articulamos a sala de aula como um cenário de criatividade, inovação e transformação social, científica e intelectual. Entendemos que colocar essa formação à altura de seu tempo - no século 21 - pressupõe romper paradigmas e percursos sedimentados pela educação mundial (ONU, 2020).

Apoiamos as invenções robóticas do aluno da Educação Básica de modo que a sua autonomia seja "[...] como um processo contínuo de descobertas e transformações da própria [aprendizagem]. Igualmente necessária é a criatividade, entendida como a capacidade humana de inovar e estabelecer algo novo [para o mundo]" (BARBOSA; LOPES, 2020, p. 274). Dessa forma, a ideia não é simplesmente desenvolver uma invenção tecnológica, 
enquanto se aprende Matemática, mas colocar o aluno como cientista e não como repetidor de informações (PAPERT, 2008; RESNICK, 2017; BLIKSTEIN; VALENTE; MOURA, 2020), sendo capaz de beneficiar pessoas em sociedade, como, por exemplo, pessoas acometidas com a doença de Parkinson, a partir de invenções científico-tecnológicas na forma de jogos digitais e dispositivos robóticos. Para tanto, a invenção em sala de aula de Matemática não deve se limitar ao conhecimento científico-tecnológico, tampouco aos testes padronizados (FREITAS, 2015), "proporcionando uma formação fragmentada - [mas, valorizar uma formação humana, intelectual], crítica e libertadora" (BARBOSA; LOPES, 2020, p. 274), corroborando o processo contínuo de descobertas em fazer ciência com a Matemática.

Em vez de conteúdo-exercícios-respostas, o trabalho com a produção de jogos e dispositivos de robótica a partir das características do Pensamento Computacional (PC) busca privilegiar a ação-compreensão-invenção e resultados do aluno em Matemática (AZEVEDO; MALTEMPI, 2018; 2019), bem como o seu pensar sobre o próprio pensar (PAPERT, 2008). Não é o simples fato de incentivar a habilidade de codificar um programa ou de construir um eletrônico como fim em si mesmo, o objetivo é usar o PC para forjar ideias para aprender: a se comunicar e a resolver problemas (PAPERT, 2008; WING, 2007), a pensar (GUZDIAL, 2008), a planejar, formular e propor soluções científico-tecnológicas (BARBA, 2016).

Diante do exposto, nosso objetivo é identificar e analisar as características do Pensamento Computacional à formação em Matemática a partir da produção de jogos digitais e dispositivos robóticos destinados ao tratamento de sintomas da doença de Parkinson. Norteados pela pesquisa qualitativa, a produção de dados foi realizada com alunos do Ensino Médio do IF-Goiano, no cenário de formação/pesquisa do Projeto Mattics. Assim sendo, inferimos resultados sobre as características do PC à formação matemática dos alunos, a partir dos cenários [recortes] contextuais marcados por invenções e discursos dos pesquisados.

\section{Contexto Formativo em Matemática: invenções robóticas e doença de Parkinson}

No contexto formativo em Matemática, negamos o processo impositivo pedagógico e colocamos em suspensão a produção de eletrônicos (jogos e dispositivos robóticos) como um fim em si mesmo. Consideramos que os eletrônicos nas aulas de Matemática não são ferramentas de ensino, mas matérias-primas de construção, desenvolvimento científicocriativo e expressão pessoal do aluno (AZEVEDO; MALTEMPI, 2020). À medida que os alunos trabalham juntos em projetos, “[...] produzem não apenas teias de conceitos, mas também conjuntos de estratégias de criar coisas, para resolver problemas e comunicar ideias" 
(RESNICK, 2017, p. 54, tradução nossa). E no processo de aprender a programar um jogo digital associado ao dispositivo robótico, o aluno pode adquirir um senso mais elaborado da Ciência, da Matemática, da Arte em construir modelos intelectuais e úteis à sociedade (PAPERT, 2008). Para isso, reconhecemos que a exploração da robótica nas aulas, com o uso de materiais de baixo custo, precisa ser planejada e bem articulada para não se reduzir aos mesmos moldes da repulsa ao fazer e aprender Matemática pelo estudante.

Centramos no desenvolvimento do processo científico-criativo do aluno, entendido como atitude para gerar ideias, aprimorá-las e comunicá-las nas diferentes áreas do conhecimento em sociedade pela Matemática e Computação (RESNICK, 2017; GONTIJO, 2007; PAPERT, 2008). A proposta de se construir eletrônicos, a partir da utilização de linguagem de programação e sucatas, no contexto de formação matemática, não é uma tarefa simples. Isso porque pressupõe ações efetivas e integradoras, que requerem um envolvimento intenso dos alunos e dos professores como construtores de contextos e agentes de mudanças. A respeito disso, torna-se fundamental que o professor medeie "[...] processos e produtos de desenvolvimento para criar oportunidades de reflexão e para desenvolver a consciência do aluno quanto às ideias e estratégias que são usadas [no processo de invenção científicotecnológica]" (BLIKSTEIN; VALENTE, 2019, p. 255, tradução nossa).

Tais eletrônicos se caracterizam como potencialidade de serem usados em sociedade (RESNICK, 2017) e uma dessas potencialidades é a de unir os jogos digitais aos dispositivos robóticos, produzidos em sala de aula, para tratamento de sintomas específicos da doença de Parkinson. Sendo uma doença de "[...] caráter crônico e progressivo, que promove complicações motoras com prejuízo na coordenação motora global e limitações funcionais que podem interferir de forma significativa na qualidade de vida particular ou geral do paciente" (SANTOS et al., 2017, p. 33), o Parkinson pode ser retardado estrategicamente com sessões fisioterapêuticas, que utilizam jogos digitais específicos e dispositivos robóticos meticulosamente produzidos às necessidades dos pacientes (STURKENBOOM et al., 2008; MENDES et al., 2012; GALNA et al., 2014). A fim de exemplificar tais sessões fisioterapêuticas, destacamos alguns jogos e dispositivos robóticos desenvolvidos pelos alunos $^{1234}$ do Mattics e utilizados no Hospital Dia do Idoso, na Figura 1.

\footnotetext{
${ }^{1} C f$. Disponível em: https://youtu.be/ZozS-Jf4OUg

${ }^{2} C f$. Disponível em: https://youtu.be/n9FfyZj_h0g

${ }^{3} C f$. Disponível em: https://youtu.be/1 tSFikTJpU

${ }^{4} C f$. Disponível em: https://youtu.be/15gEq8NC16s
} 


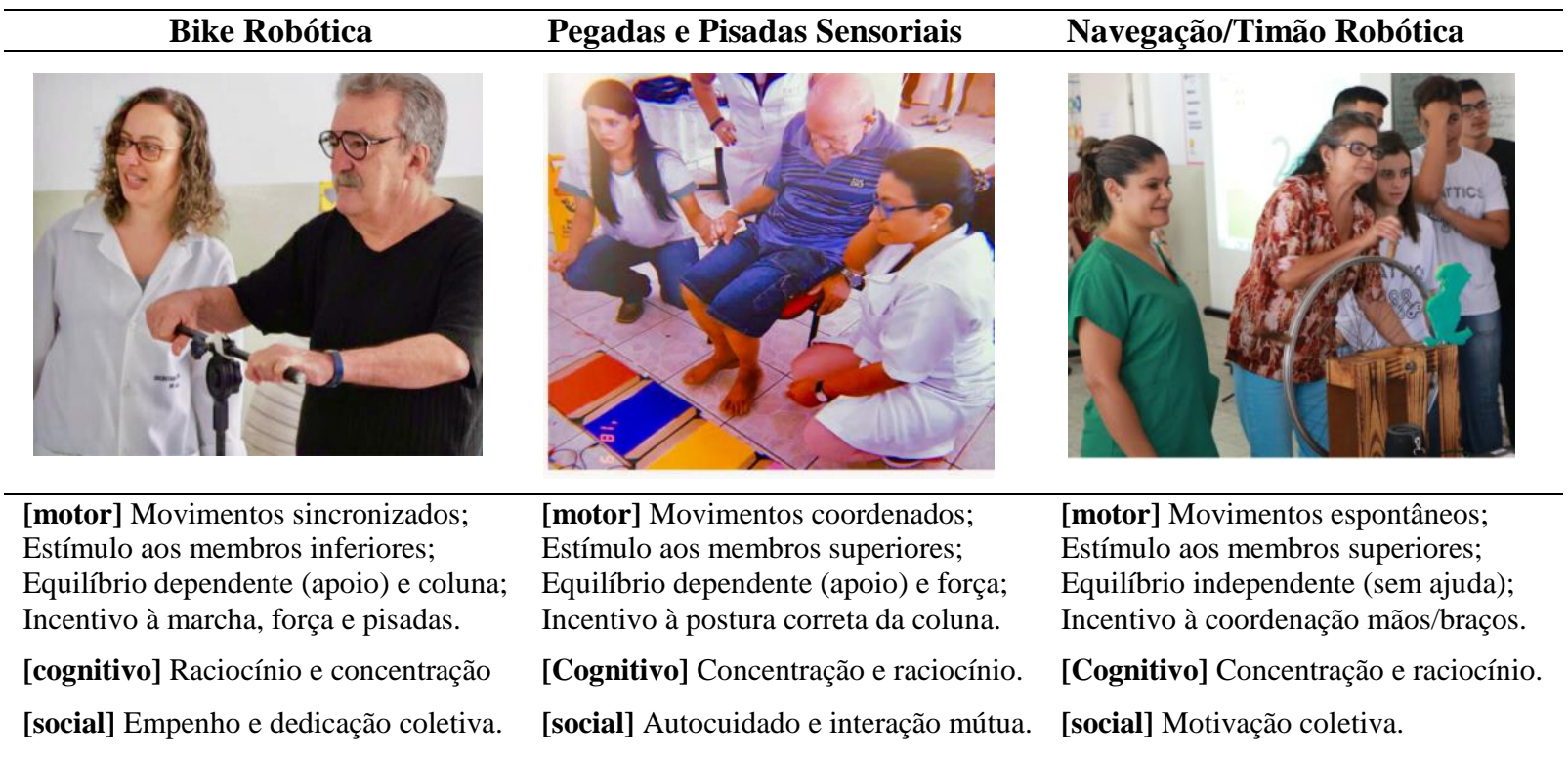

Figura 1 - Sessões de físioterapia: Dispositivos robóticos desenvolvidos ao tratamento de Parkinson pelos estudantes do Projeto Mattics do IF-Goiano.

Fonte: Dados da Pesquisa $(2018,2019)$

Os jogos e dispositivos robóticos desenvolvidos (Figura 1) auxiliam no tratamento de sintomas da doença (dada em três níveis de comodidade). Isso porque, estimulam habilidades motoras e cognitivas, além da concentração e sentidos dos acometidos (MIRELMAN et al., 2011). Os eletrônicos estabelecem, também, uma conexão entre um ambiente real e um ambiente virtual, proporcionando interação em tempo real e o estímulo de diversos movimentos corporais, promovendo melhora das capacidades biomotoras (SANTOS et al., 2017). Conforme área médica do projeto Mattics, tais sessões fisioterápicas com os jogos e dispositivos robóticos específicos podem provocar um aumento de liberação da dopamina, haja vista que ela se origina pelo processo de aprendizagem e das características ambientais, encorajando o paciente a participar das sessões e deixando-o mais motivando frente ao seu tratamento (GALNA et al., 2014; KOEPP et al., 1998).

\section{Pensamento computacional e formação matemática}

O termo pensamento computacional (PC) foi usado por Papert, na década de 1990, como possibilidade de forjar ideias mais acessíveis e poderosas para a construção de conhecimento em distintas áreas, entre as quais se inclui a Matemática. Um entendimento comum é que pensar computacionalmente pressupõe o uso do computador, confundindo este pensamento com a manipulação de máquinas ou desenvolvimento de um programa de computador. Não se trata de capacidade de manusear aplicativos eletrônicos (jogos e robótica), tampouco de um modo operante de executar tarefas repetitivas, limitando-se o 
processo criativo e investigativo do aluno. O PC é um modo de forjar ideias à aprendizagem ativa como pensador criativo-inventivo (PAPERT, 1996; 2008).

Há várias definições do Pensamento Computacional que atribuem significados, conceitos e resultados próprios. Porém, há um consenso de que ele poderia vir a ser reconhecido, nas palavras de Barba (2016) e Papert (2008), como capacidade de gerar ideias e transformá-las em um processo sistemático no qual se constrói soluções a problemas encaminhados, não necessariamente derivados da ciência da computação, mas aplicáveis em qualquer domínio do conhecimento à sociedade. O PC pode incentivar a pensar como um arquiteto, um matemático, um artista, um músico, e a como desenvolver ideias lógicointuitivas e criativas para mobilização de significados matemáticos durante a produção de jogos e dispositivos robóticos (RESNICK, 2017; WING, 2011; AZEVEDO, et al., 2018).

Para Wing (2011), o termo PC é definido como resolver problemas e projetar ideias computacionais, carregando elementos da ciência da computação, entre os quais se destacam: Decomposição, Algoritmo, Abstração e Reconhecimento de padrões. Conforme Wing (2011), a decomposição busca dividir um problema em partes menores a fim de encontrar soluções ao todo. O reconhecimento de padrões contribui na identificação de processos que se repetem lógico e ordenadamente. Tal reconhecimento de padrões pode ser encontrado no campo da Matemática através das leis de formação ou regularidades, como funções, sequências/séries aritméticas e geométricas, etc., bem como na área da computação por meio da construção de condicionais, funções recursivas e comandos de repetição de um determinado sistema.

A abstração é um processo de pensamento que identifica e extrai informações entendidas como essenciais do artefato ou ações de execução (sequências de algoritmos, sistema paralelo, etc.), favorecendo o pensar sobre eles. Também podemos entender a abstração a partir da visão decorrente de Papert (2008) acerca do pensar sobre o pensar, possibilitado pelo confronto das ideias iniciais do aprendiz com o resultado obtido na execução de um programa, o que o leva a traçar novas estratégias para a solução buscada, favorecendo o aprofundamento da compreensão lógico-analítica de um determinado conhecimento. Por fim, o algoritmo pode ser empreendido como um conjunto de regras lógico-procedurais e analíticas que, definidamente construído, permite a solução de um problema em um número finito de etapas (AZEVEDO; MALTEMPI, 2019; 2020).

A ideia do PC não é de se centrar no algoritmo em si mesmo, tampouco nos códigos de programação e seus derivados procedurais (sintaxe, algoritmo, compilação, etc.). Pelo contrário, é o modo de desenvolver o encadeamento da lógica, curiosidade, formulação de estratégias e, por conseguinte, concatenação de ideias (DENNING, 2017; WING, 2011; 
2016). Tendo em vista tal compreensão sobre o PC, não podemos incorporá-lo de qualquer forma no contexto escolar, aqui, em especial, ao processo formativo em Matemática do Ensino Médio. É preciso encorajar e incentivar a lógica, curiosidade e formulação de ideias e estratégias dos alunos. Nossa visão do PC é justamente essa, de modo que todos possam se beneficiar dele, desde um cientista da área da computação até um aluno do Ensino Médio.

Não basta apenas lançar olhares para os benefícios que o PC pode trazer ao ensino de modo geral, é preciso refletir sobre como podemos incorporá-lo no processo formativo do aluno em um ambiente de invenção e coletividade. Desenvolver ideias originais que atendam a necessidade de contribuir com o tratamento de Parkinson é uma forma de vislumbrar caminhos que considerem o PC ao longo do processo de produção e aprendizagem. Assim, entendemos que o processo de formação não pode ser reduzido ao ato simplista em desenvolver novas coisas, tampouco reduzir o processo de aprendizagem à mera instrução, mas possibilitar caminhos férteis de depuração, análise e reflexão dos conhecimentos matemáticos. Isso porque uma das melhores formas de desenvolver o PC é incentivar que os alunos "trabalhem em projetos baseados em seus interesses, depurações e inovações - em colaborações” (RESNICK, 2017, p. 16, tradução nossa), em vez de ficarem sentados ouvindo o professor. Assim sendo, as ideias do PC se estruturam na concepção de que os alunos possam: coordenar e construir novos conhecimentos (WING, 2006); desenvolver a lógica de programação - análise, abstração e depuração (BARBA, 2016; DENNING, 2017); e propor ideias e soluções a problemas encaminhados (PAPERT, 1988; RESNICK, 2012; 2017).

Neste sentido, os alunos podem assumir, durante o processo formativo em Matemática, à luz das ideias do PC, a posição de ativo-construtores, uma vez que nada é dado pronto a eles, mas são favorecidas situações para que possam: pensar, conjecturar, criar, errar e compreender ideias de Matemática de forma lógica e contextual-aplicada, tendo a chance de encontrar soluções para problemas reais encaminhados. Neste interim, avançamos à seção metodológica, a fim de compreender o percurso de pesquisa, seus sujeitos e instrumentos.

\section{Percurso metodológico}

Considerando o processo formativo em Matemática que leva em conta as ideias do PC quando se produzem jogos e dispositivos robóticos, destinados ao tratamento da doença de Parkinson, este trabalho norteia-se pelos pressupostos qualitativos de pesquisa, pois busca "[...] atingir aspectos humanos sem passar pelos crivos da mensuração, sem partir de métodos previamente definidos e, portanto, sem ficar preso a quantificadores e aos cálculos 
recorrentes" (BICUDO, 2006, p. 107). Desse modo, negamos a neutralidade do pesquisador durante todo processo investigativo e consideramos que há sempre um aspecto subjetivo a ser considerado (TRIVIÑOS, 2009; BOGDAN; BIKLEN, 1994).

A pesquisa foi realizada no âmbito do Projeto Mattics com a participação de 30 alunos do Ensino Médio do IF-Goiano, em Ipameri (GO), com visitas mensais ao Hospital Dia do Idoso (conhecido por Hospital do Idoso), em Anápolis (GO). Esse Projeto acontece no contra turno semanalmente ao longo do ano letivo e, no final de cada mês, os alunos participam das sessões fisioterapêuticas. Desde 2018, 30 jogos digitais e 15 dispositivos robóticos foram desenvolvidos pelos estudantes com a mediação do professor-pesquisador, com o auxílio de profissionais da computação e da área médica - beneficiando dezenas de idosos com o retardamento de sintomas da doença de Parkinson. Nesta pesquisa, trazemos à discussãoanálise a produção e uso do jogo Pé de Café e do dispositivo robótico regador. Para a construção deste jogo, ao longo de 10 encontros de 180 minutos cada, escolhemos caminhos acessíveis e versáteis, carregando elementos da computação e engenharia. Fizemos uso da linguagem programação e materiais de baixo custo (sucatas, fios, cobre, etc.), adequados aos processos de construção lógico-dedutiva e abstração dos algoritmos de modo a não minar a lógica do aluno com excesso de sintaxe, formalismos ou sistemas desnecessários.

Durante a construção de jogos e dispositivos robóticos, mobilizamos diferentes conhecimentos científicos, de Engenharia, Física, Design, Matemática e Computação, mas focamos nos dois últimos neste artigo. Para registro dos dados utilizamos diversos instrumentos, como diário de campo do pesquisador, fotografias, filmagens e depoimentos dos alunos. Para a produção dos jogos e dispositivos robóticos foram utilizados os softwares ${ }^{5}$ Scratch e GeoGebra, placa MakeyMakey e placa ${ }^{6}$ BBC Micro: bit. O Scratch é um ambiente de programação baseado em blocos que se encaixam. O GeoGebra é um software de Matemática dinâmica, que combina diferentes vertentes da Matemática, como geometria, álgebra, estatística e probabilidade. $O$ Micro: bit é considerado um pequeno computador com grandes potencialidades. Seus sensores detectam movimento, luz, temperatura e magnetismo. O Makey-Makey é um controle robótico que permite criar circuitos e sistemas elétricos com materiais de baixo custo. Também utilizamos sensores e condutores de eletricidade.

Para a apresentação e análise dos dados da pesquisa, utilizaremos recortes dos diálogos e discussões gravados e anotados, bem como faremos uso dos símbolos [ ] para

5 Cf. Disponíveis em: Scratch (https://scratch.mit.edu/); GeoGebra (https://www.geogebra.org/).

6 Cf. Disponíveis em: Micro: bit (https://microbit.org/); Makey Makey (https://makeymakey.com/). 
explicitar trecho que se refira à transcrição de fala dos sujeitos. Ainda, utilizaremos os símbolos ( ) para supressão dos diálogos e contextualização. Todos os participantes da pesquisa receberam os termos de consentimento/autorização e manifestaram interesse em participar sem o anonimato de suas identidades. Salienta-se que o trabalho foi aprovado no Comitê de Ética (CEP) da Unesp, campus de Rio Claro (SP), cujo CAAE é 95768318.2.0000.5466 e parecer designado pelo código 3.243.517.

\section{Apresentação e análise de dados}

O jogo Pé de Café ${ }^{7}$ associado ao dispositivo de robótica Regador é uma das invenções do grupo de alunos como forma de atender às sessões de fisioterapia do Hospital do Idoso, à luz da recomendação do time de profissionais da área da saúde/médica. Tais eletrônicos buscam incentivar movimentos específicos e estratégicos coordenados, dando a mesma ideia do movimento de quando se rega uma planta com água usando um regador convencional. Para que essa invenção científico-tecnológica fosse possível, os grupos de alunos foram estimulados a mobilizar ideias de Matemática e aprender conceitos específicos, entre os quais se destacaram: função seno, (in)equação, além da programação e robótica. A construção desse jogo se constituiu em três principais fases, a saber: ideação; brainstorming; e depuração.

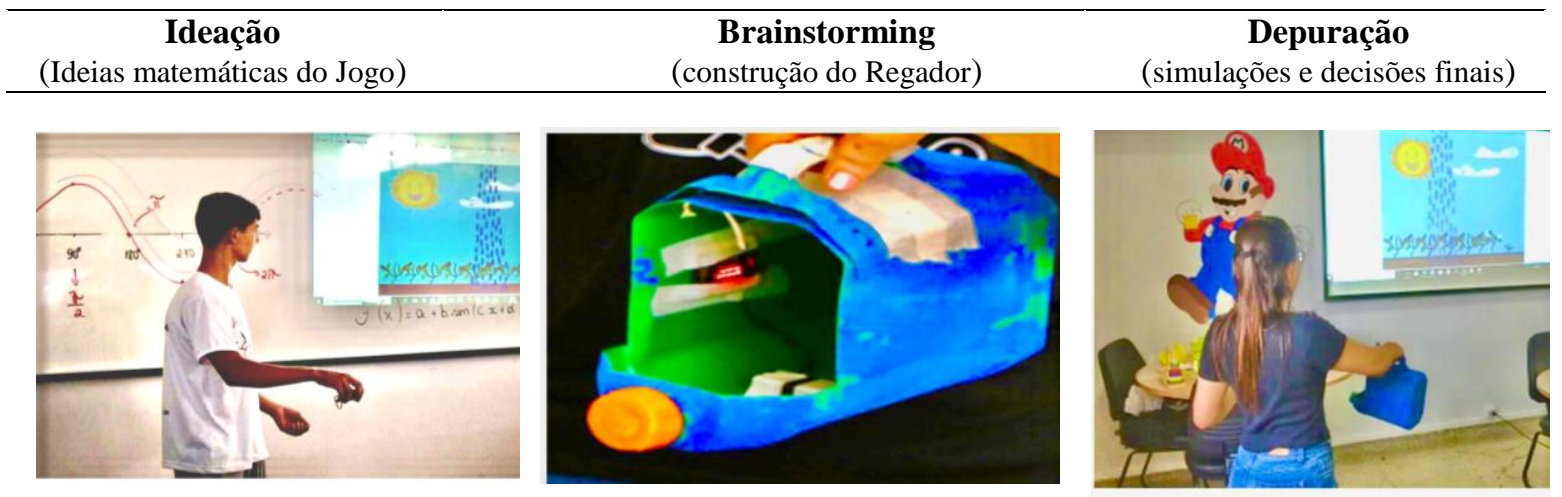

Figura 2 - Jogo Pé de Café: diferentes etapas da produção do Jogo - Função trigonométrica senoidal, regadorsensitivo e teste-análise-depuração do jogo em grupo.

Fonte: Dados da Pesquisa (2018)

Na Figura 2, da esquerda à direita, o aluno João Guilherme mobiliza ideias de Matemática, Programação e Robótica, durante a produção inicial do jogo e seus desdobramentos. Ele exemplifica a trajetória da minhoca em razão do comportamento da função senóide $[f(x)=a+b \cdot \operatorname{sen}(x \cdot c+d)]$, incluindo as suas transformações geométricas

\footnotetext{
${ }^{7}$ Cf. Disponível em: https://scratch.mit.edu/projects/302294966/
} 
(translações, rotações e reflexões), associando a elementos da programação gráfica: laço de repetição, condicionais, sistema de paralelismo, operadores lógicos e relacionais. Na imagem central, evidenciamos o dispositivo de robótica, um regador de baixo custo, composto por uma placa $B B C$ : micro-bit, circuito elétrico, tinta, garrafa de plástico, além de materiais de papelaria. A proposta de se criar esse regador, conectado ao jogo, foi a de estimular movimentos sincronizados e coordenados das mãos e braços dos pacientes, tendo em vista os fatores da doença de Parkinson associados à degeneração das capacidades motoras e mentais.

Na última imagem, a aluna testa o jogo em desenvolvimento, em interação com os demais alunos, professores e especialistas em Computação. Nesse processo, podem desenvolver ideias e mecanismos para o seu funcionamento, argumentar e receber feedback, superar desafios em conjunto, corrigir erros dos algoritmos e do regador-sensitivo, tendo a mediação pedagógico-reflexiva do professor na formalização de conceitos. Ao olhar as etapas em termos dos conceitos matemáticos e computacionais, tencionamos um espaço formativo de produção-invenção no qual a cópia deixa de ser o elemento mais importante do processo. Damos foco à participação ativa, ao erro e ao imprevisível, deixando de lado a ideia estereotipada de que o aluno precisa ser o reprodutor do professor. Oportunizamos, nesse contexto de formação, o protagonismo e a invenção-tecnológica com materiais de custo baixo, entendendo a "[...] educação [como] a mais elevada marca de aprendizagem de não ter imitadores, mas a de inspirar outros a irem além" (PAPERT, 2008, p. 82), sem deixar de dar atenção aos conteúdos curriculares matemáticos.

Tais ações vão ao encontro das ideias subjacentes ao PC, que buscam contribuir com a formação de alunos capazes de interpretar, resolver problemas, refletir e produzir artefatos tecnológicos a partir de invenções (WING, 2011). A mobilização dos conceitos matemáticos e computacionais constitui uma ampliação, traduzindo-se "na crença que nem a pessoa nem o conhecimento, incluindo a matemática, podem ser atingidos isoladamente" (PAPERT, 1988, p. 196). Relacionamos no quadro abaixo algumas ideias matemáticas e computacionais, que foram explorados ao longo da produção do jogo Pé de Café e do dispositivo robótico Regador. 
Quadro 1 - Por trás do jogo Pé de Café: conceitos matemáticos e computacionais Layout e programação em Scratch Matemática e Programação

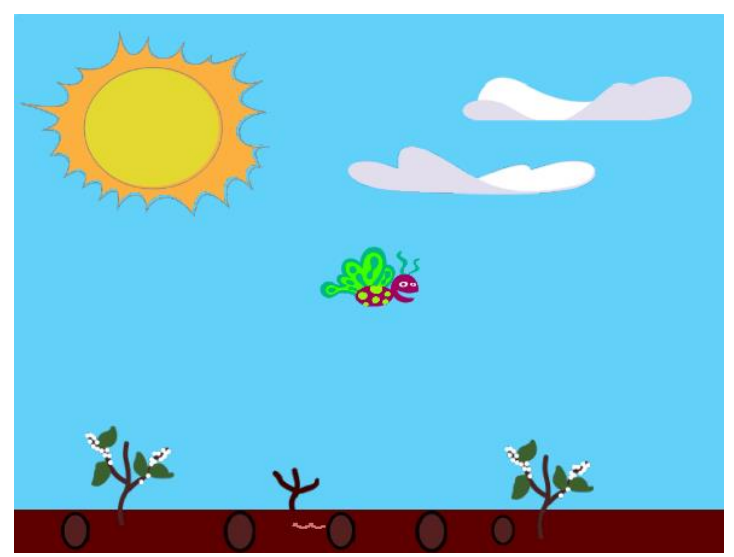

\section{[PALCO]}

O palco do jogo é baseado no plano cartesiano. Duas dimensões:

$-240 \leq x \leq 240$ (eixo horizontal: comprimento)

- $180 \leq \mathrm{y} \leq 180$ (eixo vertical: altura ou largura)

Para localizar qualquer personagem do jogo no cenário, utilizam-se as coordenadas cartesianas $(\mathbf{x}, \mathbf{y})$.

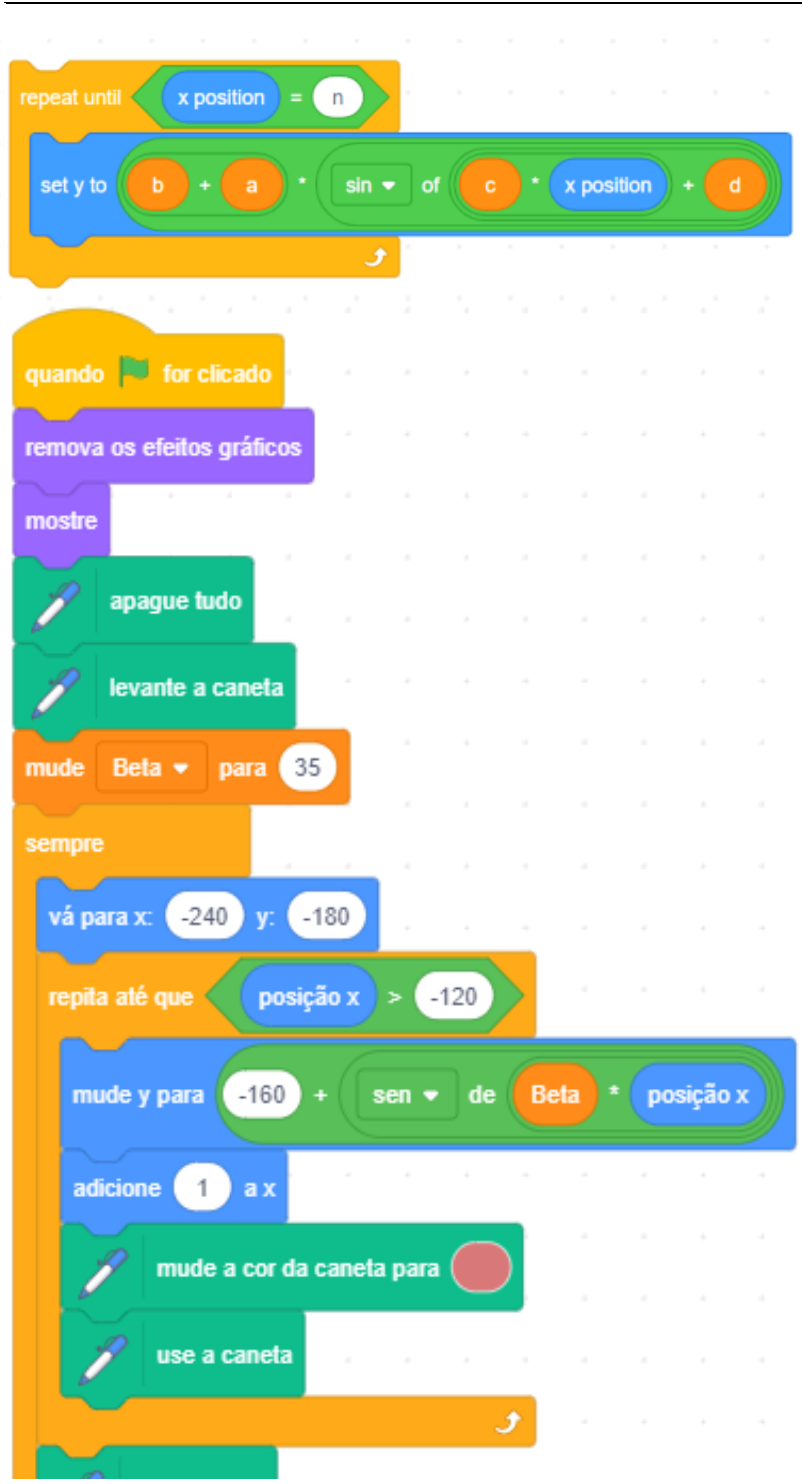

[JOGO]

Destaca-se no recorte do programa o conteúdo curricular da função trigonométrica senoidal $g(x)=\operatorname{sen}(x)$. No caso mais geral, explora-se a função $f(x)=b+a \cdot \operatorname{sen}(c . x+$ $d$ ), com $\mathrm{x} \in \mathrm{R}$, nos quais a, b, c e d são coeficientes. $\mathrm{O}$ parâmetro a no gráfico da função determina a translação vertical e o parâmetro b promove a dilatação (ou compressão) vertical do gráfico. O efeito do parâmetro c no gráfico da função altera o período da função, comprimindo ou expandindo o gráfico na horizontal, enquanto o parâmetro $\mathbf{d}$ promove a translação horizontal do gráfico. Tais valores constituem-se tanto no campo matemático quanto no da computação como variáveis e, portanto, são passíveis de serem explorados, testados e armazenados. A função é explorada no sentido de descrever a trajetória de uma minhoca no jogo, baseandose em uma oscilação repetitiva, suave e contínua. Na lei de formação, observa-se a mobilização de conceitos específicos, a saber: amplitude e regularidade. Nota-se na função canônica $f(x)=\operatorname{sen}(x)$ a ideia de uma função $f$ limitada (imagem) $-1 \leq \mathrm{f}(\mathrm{x}) \leq 1$, além do período $2 \pi$. Em termos de programação gráfica, y recebe a função senoidal [y $=-160+\operatorname{sen}\left(\beta^{*}\right.$ posição $\left.\left.\mathrm{x}\right)\right]$, sendo $\beta$ (beta) variável real [declarada]. A trajetória da minhoca (início $\mathrm{x}=-240$ ) descrita pela função senoidal repetirá até que a posição de $\mathrm{x}>$ - 120 [inequação do $1^{\circ}$ grau ou operador relacional], envolvido com o laço de repetição indefinido. 
[REGADOR] O código da placa robótica Micro-bit associado ao Scratch estrutura-se em uma sequência ordenada, que carrega passos lógicos e relacionais em um sistema de paralelismo da computação. Os dois algoritmos interligam-se para um mesmo fim: dar vida ao movimento do regador pelo BBC: micro-bit aliado à programação Scratch, tendo como base sensores que conectam software e hardware. O controle (sinalizado pela bandeira verde) indica o comando "start". A interação (looping: sempre e repita) envolve os valores angulares associados à posição de $\mathrm{x}$, em uma perspectiva intuitiva de coordenadas

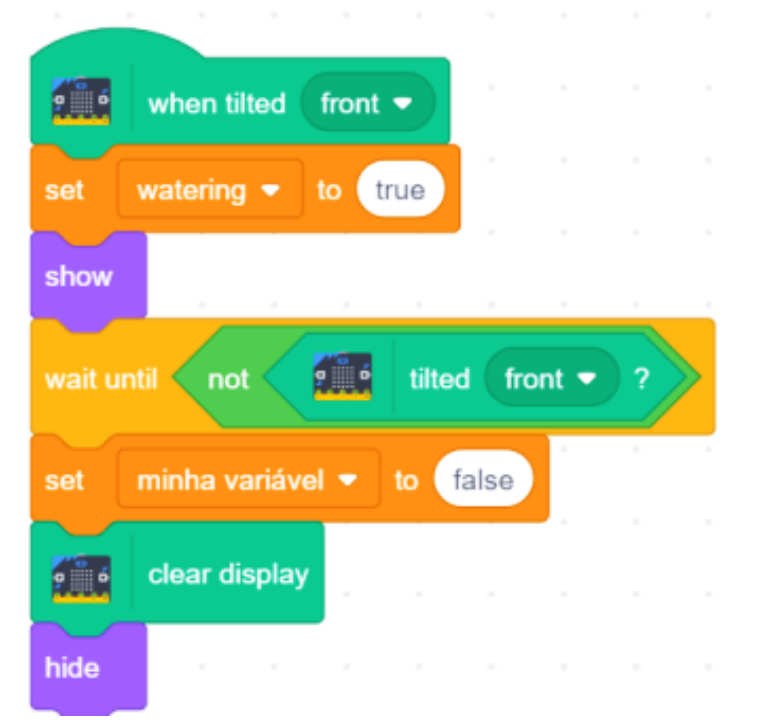

polares $\mathrm{P}=(r, \theta)$, onde $\mathrm{r}$ é o deslocamento de $\mathrm{P}$, que é gerado pelo movimento produzido do regador com o sensor da placa embutido, e o $\Theta$ é o ângulo tomado. Cada ponto polar representa a distância associada à angulação mobilizada pelo sensor. $\mathrm{O}$ comando envolve a ideia de inclinação (ângulo) associada à operação de divisão por 3 (redução de velocidade). Em termos de programação também temos a presença de sentenças falsas e verdadeiras. A ideia primitiva aqui é o chamado dado booleano (ou lógico), que assume dois valores. Há a presença de operador lógico: NÃO, ou NOT, que recebe como entrada um valor, o inverte. Toda a programação é associada aos códigos periféricos (parte física) da placa do Micro: bit. Os alunos desenvolvem sistemas de conexão e circuitos compatíveis a cada algoritmo.
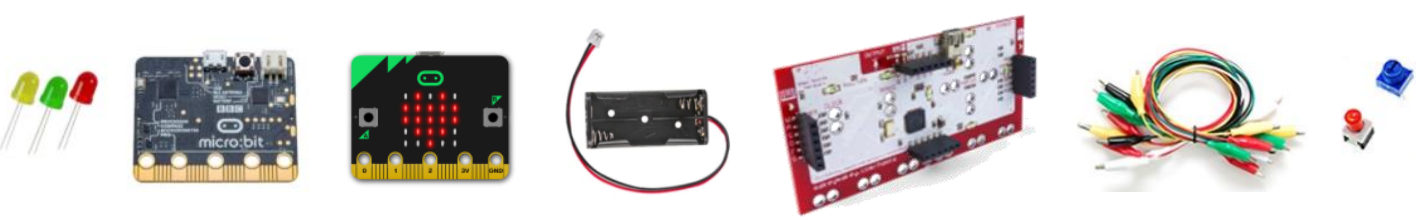

Fonte: Dados da Pesquisa (2018)

Ao trabalhar com tais conceitos, de forma intuitiva à formalização, permeados de desafios, pesquisa e engajamento, visando à produção do jogo Pé de Café e Regador destinados ao tratamento de sintomas de Parkinson, os alunos foram incentivados a questionar ideias intuitivas, a criar teorias provisórias de Matemática e relacionar conceitos da Computação e Matemática. Para entender melhor esse contexto, trazemos as ideiasconceituais mobilizadas por trás das quatro fases do crescimento do pé de café (design gráfico). 


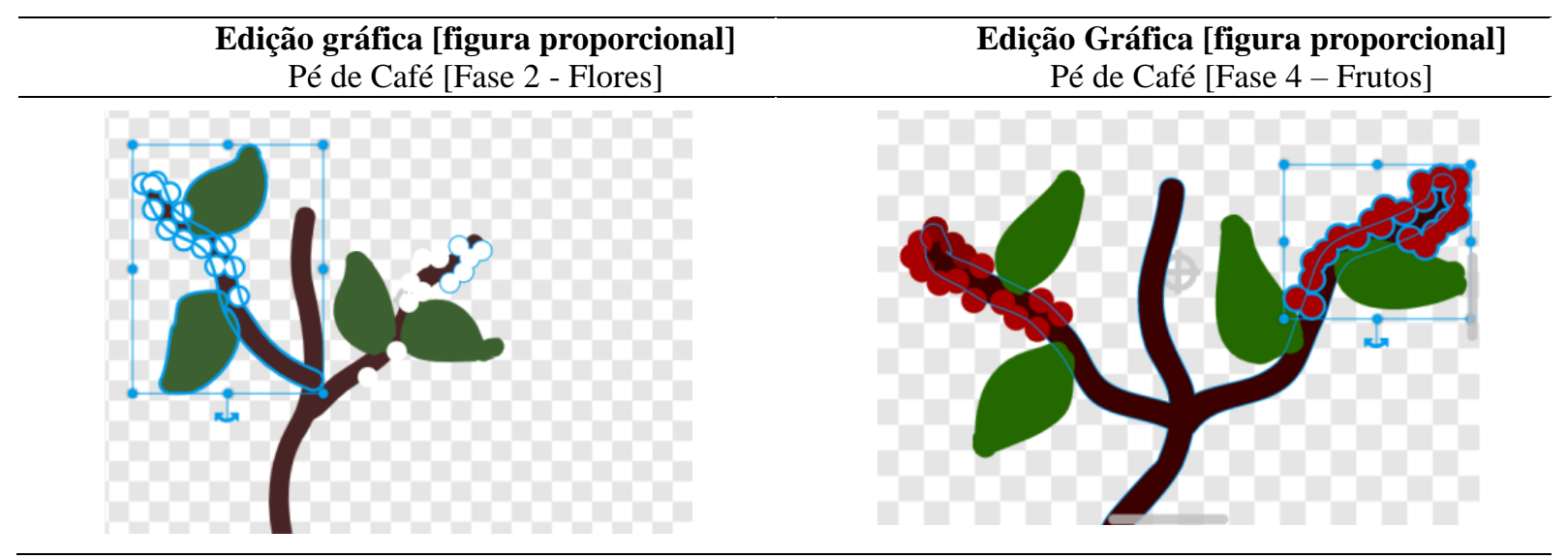

Figura 3A - Construção dos objetos vetorizados à composição do jogo Fonte: Dados da Pesquisa (2018)

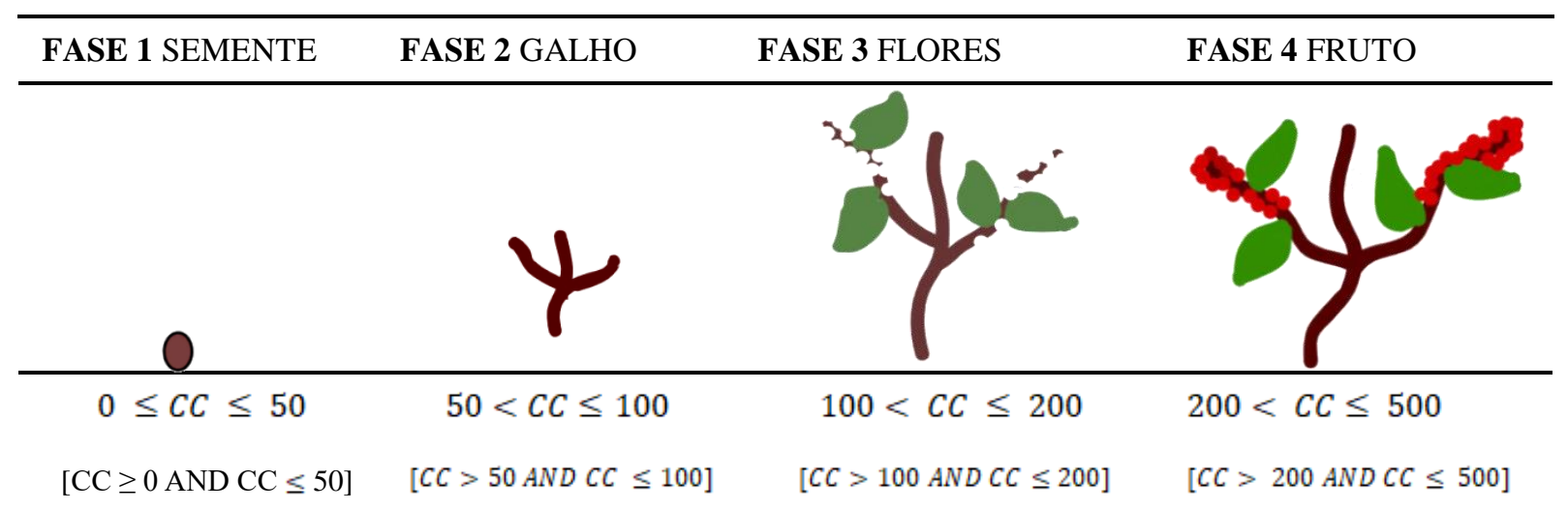

Figura 3B - Jogo Pé de Café: Fases de crescimento do pé de café - produção aliada aos conceitos matemáticos e as ideias de programação e conhecimentos de robótica Fonte: Dados da Pesquisa (2018)

Joyce: Estamos criando um esboço gráfico das quatro etapas do crescimento do pé de café. Dividimos as partes para entender o processo da evolução do cafeeiro. $O$ nosso jogo [ideias iniciais do grupo] deve estimular os movimentos das mãos e concentração do paciente ao regar as sementes de café ao decorrer do jogo [sentidos sincronizados - horizontais e verticais] (Filmagem, 2018).

Amanda: A ideia aqui é a de movimentar o regador e molhar o pé de café de tal modo que, em cada fase, ele possa crescer e oferecer bons frutos. Por trás do nosso jogo [compartilha os algoritmos à turma] (...) trabalhamos com o professor a ideia de conjunto [booleana algébrico] para fazer funcionar as transições da imagem do pé de café, que o João vai mostrar para gente... (Filmagem, 2018).

João G: (...) etapas de crescimento do cafeeiro: a semente, o broto, a árvore florida e a árvore com os frutos. Usamos os operadores [lógicos] para fazê-los funcionar como havíamos planejado em grupo. Deu trabalho. Contamos com a ajuda do professor e dividimos as funções por partes. Pegamos a ideia de fazer o café e desmembramos as suas partes até chegar nesse algoritmo, que precisávamos [mostra fragmento do algoritmo] (Filmagem, 2018).

Nas Figuras 3 (A e B), da esquerda à direita, apresentam-se as fases de crescimento do pé de café, tendo como base a discussão-reflexão da construção dos elementos do jogo pelos 
alunos. Na argumentação, a aluna Joyce enfatiza que a evolução do pé se constitui em quatro etapas menores e complementares, associando-se aos elementos da Matemática inerentes à computação. À luz da literatura do Pensamento Computacional, Papert (1996, 2008), Wing (2011), Denning (2017), Barba (2016), Resnick (2012; 2017), Azevedo e Maltempi (2020) quando há um problema complexo a ser explorado e desenvolvido pelos alunos, vislumbramse novas possibilidades para a compreensão do objeto de estudo pela decomposição das partes do jogo, contribuindo para visão particular-geral das ideias dos algoritmos geradas no coletivo. Tal etapa de quebrar as partes da estrutura do jogo é caracterizada pela decomposição na qual os desafios maiores são divididos em partes menores e vice-versa. Nesse ínterim, o contexto motor para produção de significados é favorecido pelo protagonismo dos alunos, que discutem-argumentam sobre suas próprias construções eletrônicas associadas aos matemáticos.

A busca pela compreensão da visão geral do funcionamento do jogo é orientada pelo professor, que assume a posição de parceiro da aprendizagem do aluno, ajudando-o a superar os desafios encaminhados, a buscar estratégias particulares e a sistematizar ideias específicas mobilizadas, como se nota na fala do aluno João G: “(...) contamos com a ajuda do professor e dividimos as funções por partes (...)" (Filmagem, 2018). Torna-se fundamental que o professor medeie "[...] processos e produtos de desenvolvimento para criar oportunidades de reflexão e para desenvolver a consciência do aluno quanto aos conceitos e [estratégias que são inventados]" (BLIKSTEIN; VALENTE, 2019, p. 255, tradução nossa). Neste excerto, a atribuição de sentidos dada pelo aluno, a partir da divisão do algoritmo, é uma oportunidade de coordenar e construir novos conhecimentos, contribuindo para a compreensão e, por extensão, à aprendizagem, pois a depuração [análise, abstração e correção do erro da partetodo do algoritmo] leva a uma nova descrição-reflexão e entendimento, diferente da anterior, e assim por diante, favorecendo o pensamento lógico-racional (BARBA, 2016).

Essa técnica de dividir o problema em partes menores configura-se como oportunidade de aprendizagem e é característica do PC (WING, 2011). Mostra-se indissociável ao contexto de argumentação e problematização-significado pelo aluno, que carrega ideias da lógica de programação, do sistema de símbolos e representações, do processamento sistemático e até mesmo da depuração sistemática do programa. Isso pode ser observado no contexto a seguir. 

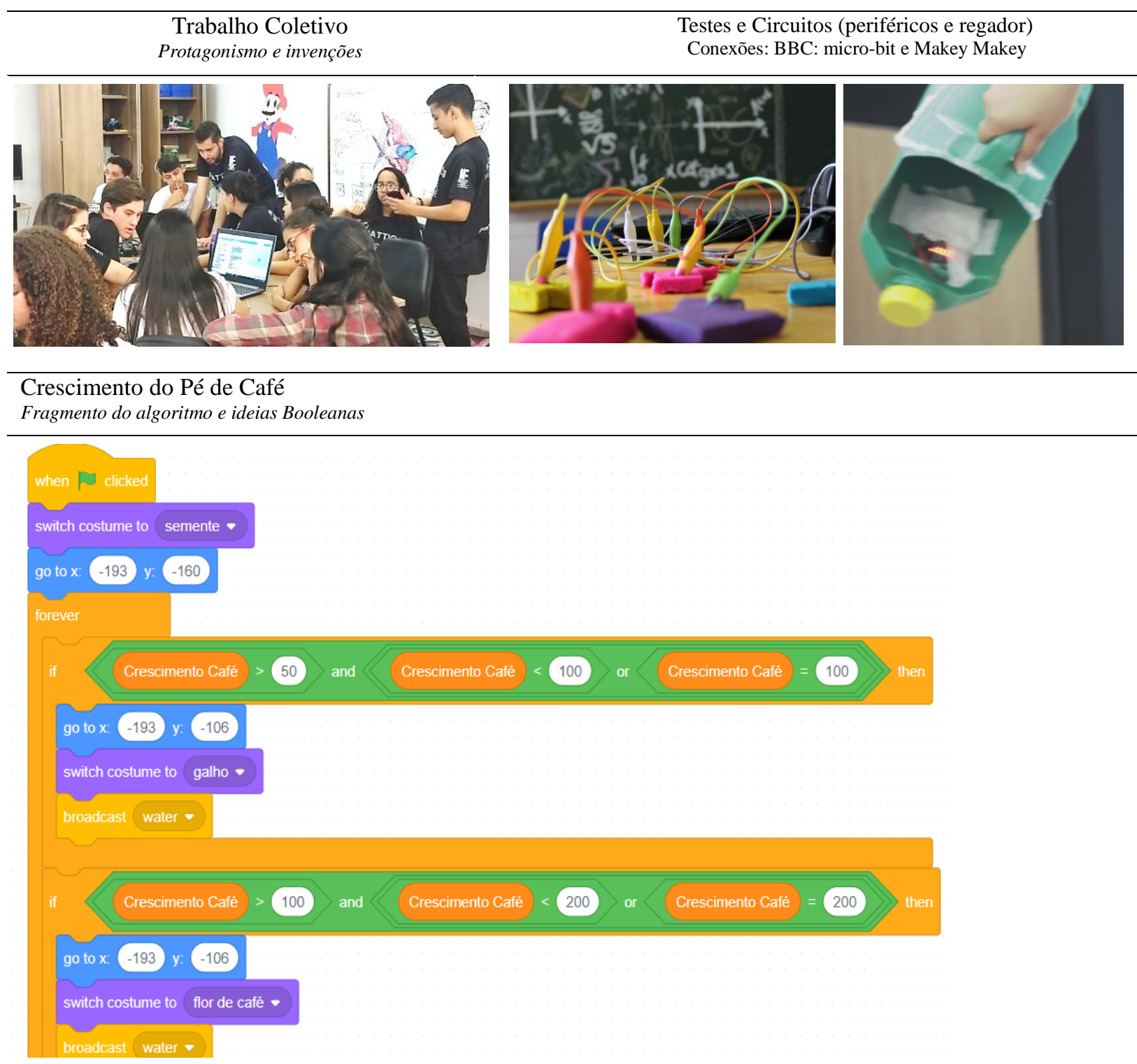

Figura 4 - Fases de crescimento do pé de café (blocos gráficos) - Discussão dos conceitos booleanos algébricos e operadores lógicos, inequações e variáveis - Testes iniciais do Regador no Makey Makey.

Fonte: Dados da Pesquisa (2018)

Carol: A ideia é a de fazer a transição das fases do crescimento do pé de café. Quando a semente receber uma quantidade $x$ de água, ela deve se transformar em galho. Com mais água fornecida pelo regador, o galho deve gerar flores $e$, por fim, na última fase, frutos. $O$ algoritmo da transição está com problema, estamos tentando encontrar a solução da passagem dessa fase para essa outra (Filmagem, 2018).

Professor: Que tal explorarmos as ideias da álgebra booleana de negação [operador not] para a transição funcionar, interligando o regador que vocês criaram? Podemos pensar sobre as sentenças verdades e falsas (...) [Discussãoexplicação de conceitos booleanos] (...) [os alunos criam coletivamente seus algoritmos] (...) O que acontece quando unimos operandos pelos operadores AND e OR? Vamos investigar? [turbilhão de ideias]. Vamos verificar se é possível fazer a mudança de fase? [Investigam hipóteses dos conceitos booleanos e dos operadores lógicos e testam valores para os intervalos numéricos definidos - de forma exploratória e conjunta] (Filmagem, 2018). 
Alexandre: No início, não estava dando certo só com o operador "ou” [união] no sistema maior de paralelismo, então tentamos apenas com o operador " $e$ " [interseção], mas também não deu certo, professor. Por fim, decidimos unir as ideias [e, ou, not] e acrescentar também a ideia do operador relacional de igualdade [=], e deu certo todo o conjunto nas variáveis [crescimento de café ao regador] (Filmagem, 2018).

Amanda: [Apresenta e discute parte do algoritmo aos colegas] Quebramos a cabeça para relacionar esses operadores. (...). Pensamos assim: Se o crescimento de café for maior que 100 e menor ou igual a 200 [100<x 200], [computação: If $C C>100$ and $<=200$, então galho, onde CC: crescimento do pé de café ], o galho vai virar a flor de café. Então, é assim, para cada quantidade de água recebida, que é nosso intervalo dos valores da coordenada $x$, o pé de café se desenvolve, em fases específicas de acordo com os intervalos numéricos definidos na estrutura do algoritmo [discussão] (Filmagem, 2018).

João G.: (...) Para o regador, ficou assim: Quando inclinada para frente >> Espere até que [não inclinado para frente] > mude [watering para false], limpe a tela, esconda. O sistema aqui vai esperar até que não esteja virada para frente. Invertemos a resposta de lógica estrutural: se sim, não. Se não, sim. Acho que o algoritmo vai funcionar. Vamos testar inicialmente na placa Makey Makey [com setas] para captação dos movimentos sensoriais do regador? Que tal? (Filmagem, 2018).

Em vez de definição-exemplo-exercícios-respostas, as ações de aprendizagem mobilizadas entre os alunos buscaram, conforme excerto acima, valorizar a compreensãoinvenção-resultados quanto ao conteúdo da álgebra booleana, em especial, intercessão e união de eventos (in)dependentes. A ideia aqui não foi focar no conteúdo em si mesmo, mas oportunizar um processo formativo significativo que não se reduz aos testes escalonáveis ou em atividades fechadas a serem meramente consumidas (PAPERT, 2008; RESNICK, 2017). Nesse sentido, buscamos oportunizar, tendo como base as características do saber e fazer matematicamente integrado ao PC, um contexto no qual os alunos possam: desenvolver e comunicar ideias; lidar com o imprevisto; propor soluções para um problema encaminhado e estabelecer relações conceituais entre os campos de Matemática e Computação (WING, 2011; PAPERT, 2008). Tencionados por essa visão, a hierarquia procedimental conteúdo-exemploexercícios é rompida nessa concepção, dando lugar à inquietação, à imaginação, à investigação e à curiosidade a partir da experimentação do aluno, na qual o processo de aprendizagem ativo passa a ser tão fundamental quanto o seu produto final (AZEVEDO; MALTEMPI, 2020).

A discussão não é verticalizada do professor ao aluno, mas antes parte da experimentação entre professor-aluno, conforme excerto “(...) que tal experimentarmos (...) vamos investigar? (...) [Testam valores]...” (Filmagem, 2018). Todos trabalham conjuntamente para um o mesmo fim e, ao mesmo tempo, buscam soluções de problemas encaminhados pela necessidade do meio, como a da proposta do grupo em construir um 
algoritmo para o crescimento do café. Nessa discussão-conjunta, observamos a seguinte discussão-explanação: "não estava dando certo só com o operador 'ou' (...) Por fim, e acrescentar também a ideia do operador relacional de igualdade [=], e deu certo" (Filmagem, 2018), que corrobora um processo não pragmático e nem linear de etapas, mas que se conjuga a partir de idas e vindas permeadas pela depuração de ideias e detecção de erro sistemático (BARBA, 2016). A “[...] questão a ser levantada a respeito do programa não é se ele está certo ou errado, mas se ele é executável” (PAPERT, 1985, p. 40). A proposta de o aluno ter a chance de construir o algoritmo a partir do erro-depuração constitui-se um cenário fértil não à compreensão de conceitos computacionais e matemáticos, até porque observar e tentar fazer da sua própria maneira é muito diferente de repetir simplesmente o que está pronto ou até mesmo substituir valor no que está feito (AZEVEDO et al., 2018).

O grupo relaciona conceitos algébricos booleanos e computacionais, operadores lógicos [and, or, not] e relacionais $[>,<,=]$ na construção coletiva-engajada do algoritmo do crescimento do pé de café. Observamos isso na argumentação-discussão da aluna Amanda à turma: "Quebramos a cabeça para relacionar esses operadores. Para cada intervalo numérico, o pé de café cresce. Pensamos assim: Se o crescimento de café for maior que 100 e menor ou igual a 200 \{If CC > 100 and > = 200, então galho\}" (Filmagem, 2018). Há uma discussão do sistema de códigos (ou sistema de símbolos e representações), mobilizada pela aluna à turma, que passa pelo planejamento de ideias e estabelecimento de estratégia para fazer o algoritmo funcionar. Entendemos que esse processamento sistemático da informação em grupo, que não se reduz ao mecanismo unilateral de receita de bolo do professor ao aluno, abre possibilidades para o aluno desenvolver ideias e inventar coisas úteis em sala de aula e, claro, lidar com situações-problema imprevisíveis quando exploram e engajam coletivamente (BARBA, 2016).

Abre também possiblidade para a sistematização de conceitos específicos e para a criação de teorias provisórias de Matemática pela abstração de ideias e de conceitos curriculares, caracterizando uma aprendizagem não encapsulada de códigos, mecanização de procedimentos e formalismos de Programação e Matemática. Entrevemos isso na mobilização da construção do algoritmo da minhoca - quando os alunos discutem o seu movimento senoidal, carregando conceitos da trigonometria, transformações e regularidades. 
Quadro 2 - Função trigonométrica: GeoGebra e Scratch - Compreensão e produção do movimento da minhoca

\begin{tabular}{l}
$\begin{array}{c}\text { Linguagem e simbologia } \\
\text { (Software GeoGebra) }\end{array}$ \\
Funções Senoidais (padrões e regularidades) \\
- Janela de Álgebra \\
\hline $\mathbf{f}(\mathrm{x})=\operatorname{sen}(\mathrm{x})$ \\
$\mathrm{g}(\mathrm{x})=\mathbf{1}+\operatorname{sen}(\mathrm{x})$ \\
$\mathbf{h}(\mathrm{x})=-\mathbf{1}+\operatorname{sen}(\mathrm{x})$ \\
$\mathrm{A}(\mathrm{x})=2 \operatorname{sen}(\mathrm{x})$ \\
$\mathbf{B}(\mathrm{x})=\operatorname{sen}(\mathrm{x}+3)$
\end{tabular}

\begin{tabular}{cc}
\hline $\begin{array}{c}\text { Linguagem e simbologia } \\
\text { (Software Scratch 3.0) }\end{array}$ & $\begin{array}{c}\text { Visualização gráfica do jogo } \\
\text { (Estrutura algorítmica da minhoca }- \text { forma senoidal) }\end{array}$ \\
\hline
\end{tabular}
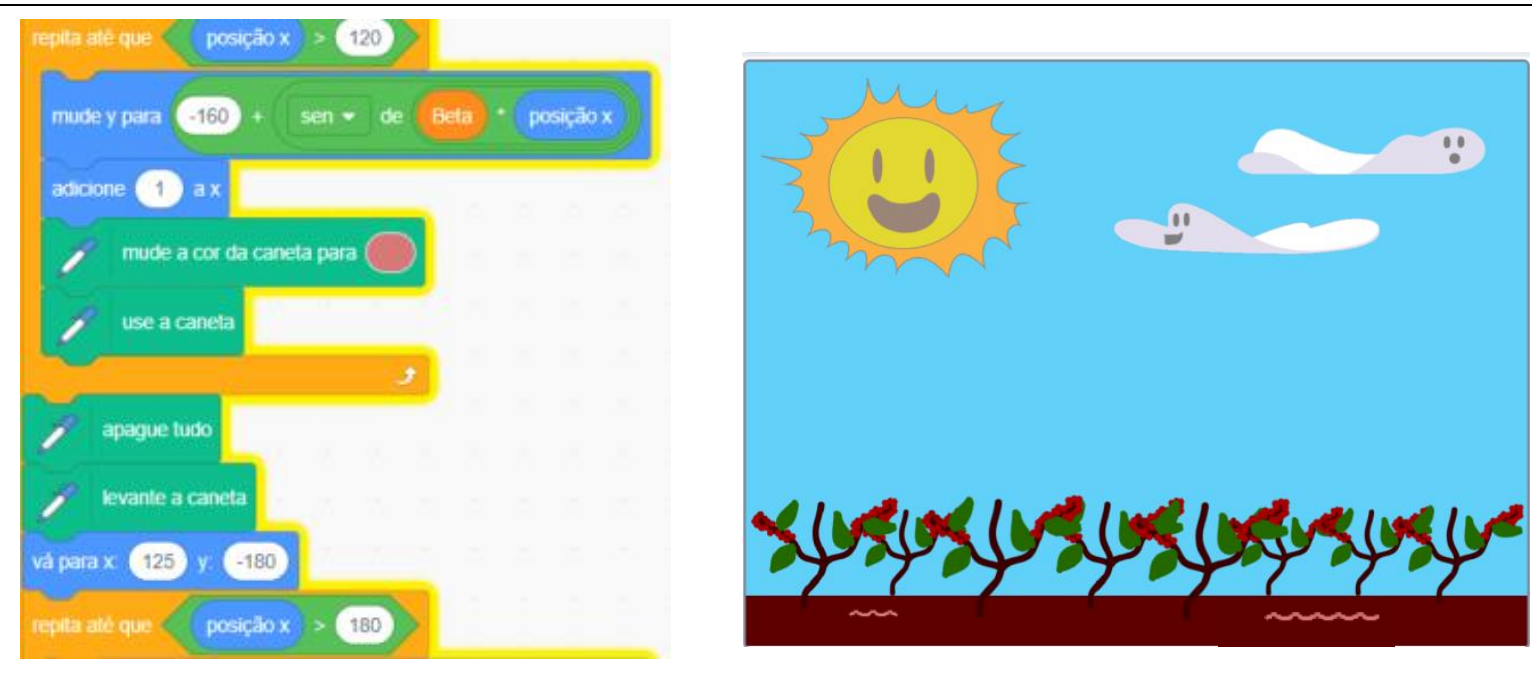

Fonte: Dados da Pesquisa (2018)

Professor: [construção dos controles deslizantes $(a, b, c, d)$ no GeoGebra]. $O$ que acontece se adicionarmos um valor positivo ou negativo na função $f(x)=$ sen $(x)$ ? Tente escrever duas funções com valores diferentes para o coeficiente a $[f(x)=a \pm \operatorname{sen}(x)$ ? [Reconhecimento de padrão e comportamento da função senóide] (Filmagem, 2018).

Amanda: Que massa! Ele fica do mesmo jeito, só sobe ou desce. Definimos para três funções escolhidas: $A(x)=0+\operatorname{sen}(x), B(x)=2+\operatorname{sen}(x)$, e $C(x)=2-\operatorname{sen}(x)$. Constatamos que as funções não alteram o período. Isso nos ajudará a pensar no algoritmo para a minhoca do jogo e suas ondulações em posições verticalizadas diferentes. Ela pode aparecer em posições diferentes (...) (Filmagem, 2018).

Professor:

(...) podemos transladar a função verticalmente quando se soma ou subtrai o valor dela por uma constante, certo? Que tal pensarmos, agora, como poderíamos fazer essa função dilatar e esticar? Afinal, a minhoca pode ter características de movimentos diferentes, não é verdade? (Filmagem, 2018). 
João G.: Pensei que quando multiplicasse a função ela ficaria de outra forma, mas, faz, sentido ficar assim... [dilatada verticalmente no mesmo ponto em x]. (...) (Filmagem, 2018).

Fernanda: Adicionamos e multiplicamos diversos valores na função e no seu argumento [ângulo]. Constatamos que ela deforma - dilata, estica e até contrai. Estamos fazendo isso também com o algoritmo no Scratch e Micro-bit. Ela vai precisar repetir [padrão] isso, então é o laço de repetição com a função envolvida. (...) A minhoca apareceu na tela em um lugar não estratégico. Precisamos somar 160 na função da minhoca, porque ela ficará na terra e pelas dimensões em y, $o$ valor mínimo é 180 [começa a explicar a lógica de funcionamento do algoritmo] (Filmagem, 2018).

No diálogo acima, os alunos exploram as ideias de transformação geométrica (como translação e regularidade) a partir da função geral senoidal $f(x)=a+b \cdot \operatorname{sen}(x \cdot c+d)$. O entendimento do conteúdo não parte da resposta dada pelo professor, mas do questionamento de ideias e levantamento de hipóteses a serem confrontadas, como se nota na fala: " $O$ que acontece se adicionarmos (...)" [e: resposta] “(...) A gente definiu para três funções escolhidas: $A(x)=0+\operatorname{sen}(x), B(x)=2+\operatorname{sen}(x)$, e $C(x)=2-\operatorname{sen}(x)(\ldots)$ constatamos que as funções..." (Filmagem, 2018). Os alunos surpreendem-se também pelo resultado não esperado: “(...) pensei que quando multiplicasse a função ela ficaria de outra forma, mas faz sentido ficar assim" (Filmagem, 2018). Nesse contexto, entendemos que a construção de teorias provisórias matemáticas no coletivo, mediante a um resultado inesperado, constitui-se como forma de ocasionar níveis de abstrações-reflexivas, que vai desde o pensamento comum (sobre um possível resultado), até a abstração-reflexiva quando se propõe novas estratégias para superar o erro (PAPERT, 2008; BARBA, 2016; AZEVEDO; MALTEMPI, 2019; 2020).

A construção de um algoritmo mobiliza-se em um processo sucessivo de abstração que compreende mecanismos lógicos e sequenciais (WING, 2014). Ao projetar o algoritmo da minhoca no jogo, por natureza, o aluno precisou desenvolver ideias gerais e específicas, entre os quais se destacam: (i) trajetória da minhoca - lei de formação senoidal; (ii) sincronização de tempo e espaço, (iii) transformações - dilatações, translações e compreensões, (iv) regulagem dos parâmetros negativos - os porquês da posição da minhoca, (v) conexão sequencial do algoritmo paralelo com demais comandos programáveis do jogo, etc. Entendemos que o processo de abstrair quando se constrói algoritmos específicos, embora relacionados, proporciona a reflexão das etapas sequenciais de entrada, execução e saída. Tal abstração permite ao aprendiz "[...] produzir algum conhecimento da sua ação ou do artefato construído [...] permite a projeção daquilo que é extraído de um nível mais baixo para um nível cognitivo mais elevado ou reorganizado em termos de conhecimento prévio" (VALENTE, 2016, p. 14). 
Um dos conhecimentos prévios utilizados na construção do algoritmo da aluna é a translação da minhoca - da soma negativa [-160] por questões lógicas do jogo: "A minhoca apareceu na tela em um lugar não estratégico [ação consequente, somaremos] -160 na função da minhoca, porque ela ficará na terra e pelas dimensões de y, o valor mínimo é 180" (Filmagem, 2018). A aluna analisa os dados de entrada do algoritmo e, por consequência, percebe que o resultado final não corresponde com seu pensamento inicial. Ao rever o processo, a aluna propõe novas ideias e constrói alternativas para a solução do problema encaminhado a partir do resultado não esperado. Esse contexto de análisedepuração são estratégias de pensamento que se constituem na formulação de um problema e na busca de respostas para ele, constituindo-se no ato de pensar como um pensador e não reprodutor de informação (WING, 2014; PAPERT, 2008; AZEVEDO et al., 2018).

A revisão-depuração do movimento da minhoca em termos do algoritmo possibilitou o grupo de alunos a buscar mais informações que lhes faltavam e, esse processo, permitiu pensar sobre novas ideias a partir do pensar já realizado, que recebe o nome de pensar-sobreo-pensar (PAPERT, 2008). Nessa busca, novos conceitos são processados e novos conhecimentos podem ser construídos pelo aprendiz ao procurar novas estratégias e ideias para aprimorar o que já se conhece. Todo esse processo de construção de algoritmo é vinculado às etapas de testagem, construção e funcionamento do regador robótico, que também acontece no Hospital, antes mesmo das sessões fisioterapêuticas, como se observa na Figura 5.

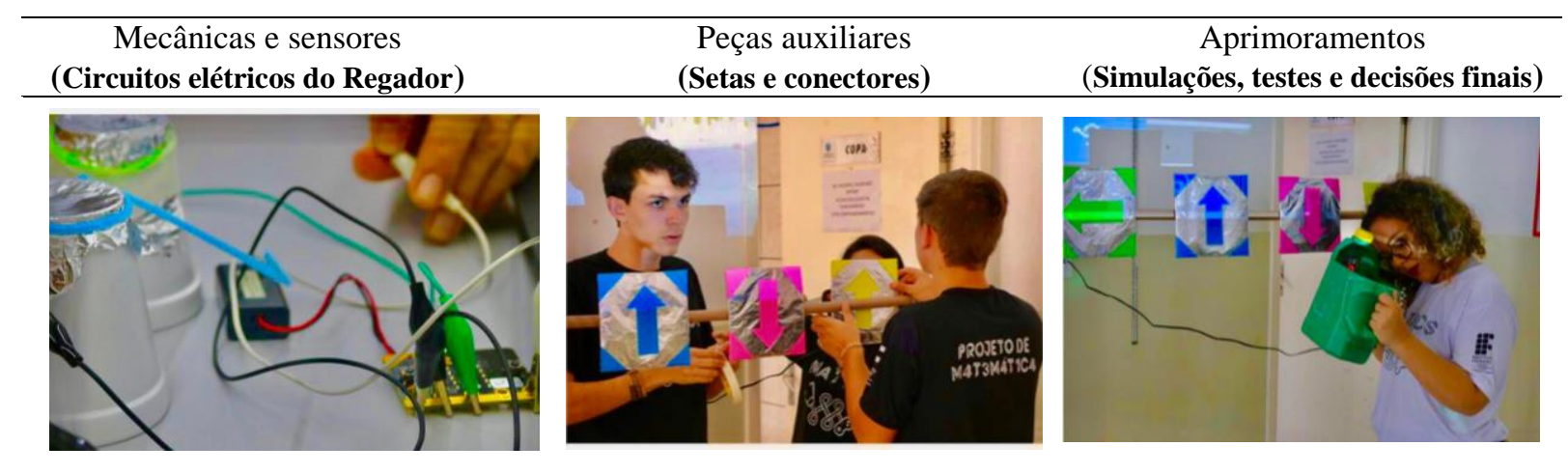

Figura 5 - Jogo Pé de Café: Etapas de construção dos jogos e dispositivos robóticos no Hospital - Testagem das voltagens e mecanismos de funcionamento às sessões de tratamento do Parkinson

Fonte: Dados da Pesquisa (2018)

Antes das sessões de fisioterapia, os alunos continuam a mobilizar ideias não só matemáticas ou computacionais. Quando fazem as testagens no hospital com os profissionais da área médica, unificam conceitos de Física, como: circuitos elétricos, sistemas paralelos ou em série, aceleração e velocidade, deslocamento, trabalho e peso. Ou seja, os jogos são testados e as velocidades ajustadas, a fim de evitar contratempos e garantir a segurança de 
todos. A responsabilidade é vinculada não só aos profissionais da área médica, mas toda equipe do projeto. Só depois da aprovação da equipe, que as invenções são aplicadas ao tratamento. Depois de todos os equipamentos testados e devidamente alinhados: carga elétrica, peso do equipamento e manutenção do espaço para o uso das invenções científicotecnológicas: Jogo Pé de Café e Regador-Robótico, as sessões de tratamento são aprovadas e iniciadas.

$\begin{gathered}\text { Manipulação e Sincronismo } \\ \text { (Sessão de Fisioterapia) }\end{gathered}$
$\begin{gathered}\text { Concentração e auxílio médico } \\ \text { (Sessão de Fisioterapia) }\end{gathered}$

Figura 6 - Sessão de Fisioterapia: Uso do jogo Pé de Café no Hospital Dia do Idoso Fonte: Dados da Pesquisa (2018)

Conforme a Figura 6, mais do que estudar conteúdos específicos que se encerram em si mesmos, os alunos são incentivados a trabalhar coletivamente, a desenvolver ideias e propostas para um fim útil em sociedade e não para testes padronizados, ajudando pessoas e trazendo bem-estar aos acometidos com a doença de Parkinson. A ideia não é só molhar as sementes de café e fazê-las germinar, é a de estimular a concentração e os movimentos coordenados do corpo dos pacientes, acompanhados por profissionais da área da saúde. Os jogos associados aos dispositivos robóticos estimulam movimentos estratégicos dos pacientes, provocando sensações diversas e encorajando segmentos corporais de posição, reflexão e aceleração. Tais estímulos melhoram tanto a propriocepção do paciente ${ }^{8}$, a amplitude de movimentos (motricidade) quanto à abdução, flexão e extensão de membros dos pacientes, exercendo estímulo aos músculos e dando mais coordenação motora, flexibilidade, resistência e força global e localmente do corpo (SIN; LEE, 2013; ARUIN; SHIRATORI, 2003).

Nessa perspectiva em desenvolver jogos digitais e dispositivos robóticos, à luz das ideias do PC (PAPERT, 2008; RESNICK, 2017), entendemos que os alunos forjam ideias e desenvolvem soluções a problemas reais encaminhados à sociedade. Tais ideias fomentam aspectos fundantes à formação em Matemática, no qual o aluno, na sua própria voz,

\footnotetext{
${ }^{8} C f .:$ Depoimento do paciente. Disponível em: https://youtu.be/mAAIWnzlR4M.
} 
materializa suas invenções com engajamento, expertise, responsabilidade intelectual e social (PAPERT; HAREL, 1991).

\section{Conclusões}

Tendo em vista o objetivo deste artigo, identificamos e discutimos as principais características do pensamento computacional à formação em Matemática, ao longo do processo de invenção-compreensão-resultados ao tratamento de Parkinson: algoritmo, decomposição, abstração e reconhecimento de padrões. Elas se conjugam como formas de pensamento e estratégias que são atribuídas pelos próprios estudantes quando desenvolvem invenções à sociedade, tendo como base a Matemática e a Computação. Ao analisar tais características, inferimos que elas se estruturam como habilidades importantes à formação matemática dos alunos, pois incentivam o processo de reflexão-argumentação e desenvolvimento do pensamento lógico-racional, favorecendo a compreensão de conceitos como uma rede de significados. Ao mobilizar a exploração das características do PC na produção do jogo Pé de Café e dispositivo robótico Regador, os alunos centraram esforços para compreender parte-todo de um sistema algoritmo, perfazendo análise-conjecturas dos termos computacionais às leis de formação das funções trigonométricas, relacionais e recursivas (algoritmos e reconhecimento de padrões).

Abstração e decomposição, que também se constituem como características do PC (WING, 2011; PAPERT, 2008), se evidenciam, explícita e implicitamente, na análise de comportamento (dilatação, compressão, etc.) das funções matemáticas desenvolvidas em linguagem de programação e na compreensão-analítica dos movimentos plotados em software específicos de Matemática. Isso porque, tais características do PC não se dissociam dos processos de argumentação-reflexão e pensamento-estratégias definidos pelos próprios alunos ao longo do processo formativo em Matemática. Nesse sentido, percebemos que, ao abordarem uma tarefa complexa, como a do algoritmo da função senóide associada ao regador-robótico, os alunos comunicaram ativamente ideias e soluções, refletiram sobre suas construções e testaram teorias-hipóteses a partir da argumentação-depuração de estratégias e pensamentos lógico-explicativos das criações e ideações realizadas coletivamente.

Ao dividir um problema em partes e, por extensão, entender seu funcionamento global, os alunos experimentaram o trânsito de pensamento geral-específico e vice-versa, e trabalharam com a lógica dos operadores, enquanto articulavam conhecimentos científicos e tecnológicos para o funcionamento do jogo vinculado ao dispositivo robótico. Ao pensar na 
articulação de conhecimentos científicos e tecnológicos à invenção de possíveis soluções à sociedade, a sala de aula de Matemática se transforma em lugar de diálogo, investigação, curiosidade, inovação com uso de materiais de custo baixo, em vez de listas de exercícios pautadas na pedagogia do treinamento. Nessa perspectiva, o aluno, ao ter a oportunidade de questionar teorias, lidar com frustações, inventar objetos e usar os seus conhecimentos, pôde assumir a posição de cientista. Em particular, a construção do Pé de Café e do regadorrobótico para o tratamento da doença de Parkinson, muito além de privilegiar características do PC e conteúdos curriculares de Matemática, constituiu-se como proposta de aprendizagem emergente à sociedade, evidenciando uma formação mais contextual e corresponsável e incentivando estudantes a serem pensadores criativos, capazes de lidar com imprevistos e frustrações, desenvolvendo senso de responsabilidade.

No entanto, redobramos o cuidado com os modismos do século 21 , haja vista que não se pode reduzir a formação em Matemática ao ato minimalista de fazer por fazer artefatos com a tecnologia. Assim, nossos olhares se fitam mais no engajamento criativo, científico, inventivo e intelectual do aluno do que simplesmente no manuseio de tecnologias. Não defendemos a tese de que a organização de ensino para a formação matemática com a produção de jogos e dispositivos robóticos para o tratamento da doença de Parkinson, baseadas nas concepções teóricas do PC, seja a melhor. Apenas reforçamos que ela potencializa o incentivo ao espírito de investigação, curiosidade e criatividade do aluno em sala de aula, tornando-o capaz de interpretar situações reais e propor soluções meticulosamente desenvolvidas ao tratamento motor, cognitivo e social-motivacional dos pacientes acometidos com a doença de Parkinson. Assim, essa abordagem não se limita a cópia dos conteúdos curriculares de Matemática e da área computacional, dentro da sala de aula. Utiliza-se o que já existe e, a partir desse princípio, avança-se para a construção de conhecimentos - preconizados pelo desenvolvimento científico-tecnológicos para um bem comum em sociedade.

\section{Agradecimentos}

Nosso reconhecimento a todo time de profissionais do Projeto Mattics. Em especial, aos excelsos alunos do Ensino Médio do IF-Goiano, Ipameri - GO, edição 2018/19, pela dedicação e engajamento contínuo. E também aos incríveis profissionais da computação, engenharia e saúde, que sonham de perto com as invenções científico-tecnológicas. Aos pacientes do Hospital Dia do Idoso, Anápolis - GO, vocês são amáveis e inspiradores. 


\section{Referências}

AZEVEDO, G. T., MALTEMPI, M. V.; LYRA-SILVA, G. G. M. V. (2018). Processo formativo do aluno em matemática: jogos digitais e tratamento de Parkinson. Zetetike, Campinas, v. 26, n. 3, set./dez. 2018.

AZEVEDO, G. T.; MALTEMPI, M. V. Processo Formativo em Matemática e Robótica: Construcionismo, Pensamento Computacional e Aprendizagem Criativa. Tecnologias, Sociedade e Conhecimento, v. 7, p. 85-227, 2020.

AZEVEDO, G. T.; MALTEMPI, M. V. Produções criativas de matrizes e de transformações geométricas com metodologias ativas. BoEM, Joinville, v. 7, n. 13, p. 100-119, jul./ago. 2019.

AZEVEDO, G. T.; MALTEMPI, M. V.; LYRA, G. M. V.; RIBEIRO, J. P. M (2018). Produção de games nas aulas de Matemática: por que não? Acta Scientiae, Canoas, v. 20, p. 950-966.

AZEVEDO, G. T.; MALTEMPI, M. V.; LYRA, G. M. V.; RIBEIRO, J. P. M (2020). Aprendizaje matemático y tecnologías digitales: invenciones robóticas para el tratamiento de Parkinson.

Paradigma, Maracay, v. 1, p. 81-101, 2020.

AZEVEDO, G; MALTEMPI, M. V. Processo de Aprendizagem de Matemática à luz das Metodologias Ativas e do Pensamento Computacional. Ciência \& Educação (ONLINE), v. 26, p. 1$18,2020$.

ARUIN, A; SHIRATORI, T. Anticipatory postural adjustments while sitting: The effects of different leg supports. Experimental Brain Research, Chicago, v. 151, n. 1, p.46-53, 2003. Disponível em: https://doi.org/10.1007/s00221-003-1456-y. Acesso em: 10 fev. 2019.

BARBA, L. Computacional Thinking: I do not think it means what you think it means. 2016. Disponível em: http://lorenabarba.com/blog/computational-thinking-i-do-not-think-it-means-whatyou-think-it-means/. Acesso em: 10 dez. 2019.

BARBOSA, J. G; LOPES, C., E. Insubordinação criativa como parte do legado científico de Beatriz Silva D’Ambrosio. Revista Brasileira de Pesquisa (Auto)Biográfica, Salvador, v. 05, n. 13, p. 261276, jan./abr. 2020. Disponível em: http://dx.doi.org/10.31892/rbpab2525-426X.2020.v5.n13.p261276. Acesso em: 10 jul. 2020.

BICUDO, M. A. V. Pesquisa Qualitativa e Pesquisa Qualitativa Segundo a Abordagem Fenomenológica. In: BORBA, M. C.; ARAÚJO, J. L. (org.). Pesquisa Qualitativa em Educação Matemática. São Paulo: Autêntica, 2006. p. 100-118.

BLIKSTEIN P. Travels in Troy with Freire: Technology as an agent for emancipation. In: NOGUERA P.; TORRES C. A. (ed.). Social justice education for teachers: Paulo Freire and the possible dream. Rotterdam: Sense, 2008. p. 205-244.

BLIKSTEIN, P., VALENTE, J., MOURA, E. M. Educação Maker: onde está o currículo? Revista eCurriculum, São Paulo, v. 18, n. 2, p. 523-544. abr./jun.2020. Disponível em: http://revistas.pucsp.br/curriculum/article/view/48127/32229. Acesso em: 13 abr. 2020.

BOGDAN, R; BIKLEN, S. Investigação Qualitativa em Educação: uma introdução à teoria e aos métodos. Lisboa: Porto Editora, 1994.

DENNING, P. J. Remaining Trouble Spots with Computational Thinking. Communications of the ACM, New York, v. 60, n. 6, p. 33-39, 2017. Disponível em: https://www.acm.org/about-acm/contactus. Acesso em: 13 fev. 2018. 
FREITAS, L. C. Base Nacional (Mercadológica) Comum. Blog do Freitas. 2015. Disponível em: https://avaliacaoeducacional.com/2015/07/20/base-nacional-mercadologica-comum/. Acesso em: 06 jan. 2020.

GALNA, B. et al. Retraining function in people with Parkinson's disease using the Microsoft kinect: game design and pilot testing. New York. J Neuroeng Rehabil, 2014. Disponível em: 10.1016/j.physio.2012.06.001. Acesso em: 10 nov. 2018.

GONÇALVES, G. B; LEITE; M. A. A.; PEREIRA, J. S. Influência das distintas modalidades de reabilitação sobre as disfunções motoras decorrentes da Doença de Parkinson. Revista Brasileira de Neurologia, Juiz de Fora, v. 47, n. 2, p. 22-30, 2011.

GONTIJO, C. H. Criatividade em Matemática um olhar sob a perspectiva de Sistemas. Zetetiké, Campinas, v. 15, n. 28, p. 153-172, 2007. Disponível em: https://www.scielo.br/scielo.php?pid=S0103-636X2015000100002\&script=sci_abstract\&tlng=pt. Acesso em: 10 fev. 2019.

GUZDIAL, M. Education: Paving the way for computational thinking. Communications of the ACM 51, New York, v. 51, n. 8, p. 25-27, 2008. Disponível em: http://dx.doi.org/10.1145/1378704.1378713. Acesso em: 15 set. 2008.

KOEPP, M. J. et al. Evidence for striatal dopamine release during a video game. Nature, [s.1.], v. 393, n. 6682, p. 266-268, 1998.

MENDES, F. A. S et al. Motor learning, retention and transfer after virtual-reality-based training in Parkinson's disease - effect of motor and cognitive demands of games: a longitudinal, controlled clinical study. Physiotherapy, Amsterdam, Holland. v. 98, n. 3, p. 217-220, 2012. Disponível em: 10.1016/j.physio.2012.06.001. Acesso em: 03 dez. 2008.

MIRELMAN, A. et al. Virtual Reality for Gait Training: Can It Induce Motor Learning to Enhance Complex Walking and Reduce Fall Risk in Patients with Parkinson's Disease? The Journals of Gerontology: Series A, v. 66A, n. 2, p. 234-240, feb. 2011. Disponível em: 10.1093/gerona/glq201. Acesso em: 17 jun. 2018.

ONU. Assembleia Geral das Nações Unidas. Educação de Qualidade. 2020. Disponível em: https://nacoesunidas.org/tema/ods4/. Acesso em: 18 jun. 2020.

PAPERT, S. A máquina das Crianças: repensando a escola na era informática. Porto Alegre: Artes Médicas, 2008.

PAPERT, S. An exploration in th espace of mathematics educations. Internaticional Journal of Computers for Mathematical Learning, v. 1, n. 1, p. 95-123, 1996.

PAPERT, S. Logo: Computadores e Educação. São Paulo: Brasiliense, 1988.

PAPERT, S.; HAREL, I. Constructionism: research reports and essays, 1985-1990. Norwood: Ablex Pub. Corp, 1991.

RESNICK, M. Lifelong Kindergarten: cultivating Creativity through projects, passion, peers and play. Cambridge: MIT Press, 2017.

RESNICK, M. Vamos ensinar as crianças a programar. 2012. Disponível em: https://www.ted.com/talks/mitch_resnick_let_s_teach_kids_to_code?language=pt. Acesso em: 11 nov. 2019. 
SANTANA, C. M. F. et al. Efeitos do tratamento com realidade virtual não imersiva na qualidade de vida de indivíduos com Parkinson. Revista Brasileira Geriatria, Rio de Janeiro, v. 18, n. 1, p. 49-58, 2015. Disponível em: https://www.scielo.br/pdf/rbgg/v18n1/1809-9823-rbgg-18-01-00049.pdf .

Acesso: 10 nov. 2018.

SANTOS, L. R. et al. Game terapia na doença de Parkinson: influência da adição de carga e diferentes níveis de dificuldade sobre a amplitude de movimento de abdução de ombro. Revista Ciência e Movimento, v. 25, n. 4, p. 32-38, 2017. Disponível em:

https://portalrevistas.ucb.br/index.php/RBCM/article/view/6892/pdf . Acesso em: 10 jan. 2019.

SIN, H. H.; LEE, G. C. Additional Virtual Reality Training Using Xbox Kinect in Stroke Survivors with Hemiplegia. American Journal of Physical Medicine e Rehabilitation, v. 92, n. 10, p. 871-880, 2013. Disponível em: https://pubmed.ncbi.nlm.nih.gov/24051993/. Acesso em: 10 jan. 2019.

STURKENBOOM, I. et al. Guidelines for Occupational Therapy in Parkinson's Disease Rehabilitation. Nijmegen: The Netherlands/Miami, 2008.

TRIVIÑOS, A. N. S. Introdução à pesquisa em Ciências Sociais: a pesquisa qualitativa em Educação. 18. reimp. São Paulo: Atlas, 2009.

VALENTE, J. A. Jogos digitais e educação: uma possibilidade de mudança da abordagem pedagógica no ensino formal. Revista Iberoamericana de Educação, Estados ibero-americanos, v. 70, n. 1, p. 928, jan. 2016.

VALENTE J. A.; BLIKSTEIN P. Maker education: Where is the knowledge construction?

Constructivist Foundations, v. 14, n. 3, p. 252-262, 2019. Disponível em:

https://constructivist.info/14/3/252. Acesso: 23 dez. 2019

WING, J. Computational Thinking. Carnegie Mellon University. 2007. Disponível em: http://www.cs.cmu.edu/afs/cs/usr/wing/www/Computational_Thinking.pdf. Acesso em: 02 nov. 2018.

WING, J. M. Computational Thinking Benefits Society. Social Issues in Computing. 2014.

Disponível em: http://socialissues.cs.toronto.edu/2014/01/computational-thinking/. Acesso em: 04 abr. 2019.

WING, J. M. Computational Thinking. Communications of the ACM, New York, v. 49, p. 33-35, 2006.

WING, J. M. Computational Thinking: What and Why? 2011. Disponível em: http://www.cs.cmu.edu/ CompThink/resources/TheLinkWing.pdf. Acesso em: 20 dez. 2019.

Submetido em 25 de Dezembro de 2019. Aprovado em 21 de Outubro de 2020. 